\title{
Metastasizing Pleomorphic Adenoma of the Salivary Gland
}

National Cancer Institute

\section{Source}

National Cancer Institute. Metastasizing Pleomorphic Adenoma of the Salivary Gland. NCI Thesaurus. Code C35759.

A very rare pleomorphic adenoma of the salivary glands that metastasizes inexplicably, despite the benign histopathologic features. The most common sites of metastasis are bone, lung, and head and neck. 